\title{
Research on "3+2+1" Talents Training Mode of Electrical Automation Technology Specialty in Higher Vocational Education
}

\author{
Zou Xiansheng \\ zou_xiansheng@163.com \\ Dalian Vocational \& Technical College, \\ Dalian, Liaoning, 116037, China
}

\begin{abstract}
The core of teaching reform in higher vocational colleges is the reform and innovation of talent training mode, which directly determines the quality of professional talent training. Aiming at the present situation of talent cultivation mode of electrical automation technology specialty in Higher Vocational colleges, this paper summarizes the reform course of talent cultivation mode, and puts forward a new "3+2 +1 " talent cultivation mode combining with the characteristics of talent demand of equipment manufacturing industry in Dalian. The professional diagnosis and improvement mechanism is introduced to ensure the sustained and steady development of the profession. After five years of exploration and practice, it has broken through the limitations of the training of highly skilled talents and achieved remarkable results.
\end{abstract}

Keywords-Teaching Reform, Electrical Automation Technology Major, Course, Innovation of Talent Cultivation Model, Professional Diagnosis Improvement Mechanism

\section{INTRODUCTION}

Higher vocational education is an important part of higher education in China. After more than 20 years of development, higher vocational education has gone through nothing, from weak to strong, and from the point of no attention to the various stages of development that cause the society, especially the industry and enterprises to pay attention to it, making great progress. Talent training in higher vocational colleges aims at serving regional economic and social development and focuses on the cultivation of students' professional ability and professional ability, especially their professional quality to deepen the basic requirements for the reform of personnel training mode in Higher Vocational Education through docking of professional and industrial, professional post, professional curriculum content and professional standards, professional curriculum contents and professional standards, teaching process and production process, diploma and vocational qualification certificate and vocational education and lifelong learning through deep level school enterprise cooperation and extensively explored and practiced the training mode of professional talents taking the integration of production and education as the main line. The reform and innovation of professional training mode in higher vocational colleges has always been a hot topic which is out of date.

Students in higher vocational colleges are indispensable talents in the future socialist construction in China especially under the background of the reform of China's higher education system. The cultivation of applied and operational talents will receive unprecedented attention, and the needs of society also require schools to cultivate more and more outstanding highquality operational and applied talents, which requires innovative talents training mode in Higher Vocational colleges to cultivate more talents to meet the needs of society[1].

Due to the prejudice of society to higher vocational colleges, there are more and more theoretical and researchoriented talents in the labor market, but less applied and operational practical talents, and the gap is large. This requires a new mode of innovative education teaching in Higher Vocational colleges, cultivating a large number of excellent operational talents, adapting to the needs of society, gaining reputation with high employment and quality, establishing the image of Higher Vocational colleges, and contributing to the cultivation of social talents.

In order to meet the needs of the development of the equipment manufacturing enterprises in Dalian, Dalian Vocational and Technical College has trained more competitive professional talents, explored and practiced for nearly twenty years in the reform of personnel training mode, and summed up the "3+2+1" professional personnel training mode. Through five years of teaching practice, good results have been achieved. It has a certain leading and exemplary role in the reform of the relevant professional training mode in this region.

\section{Reform Process of Professional Training Mode for} Electrical Automation Technology Professionals

Our college's electrical automation technology specialty, whose predecessor is the secondary vocational school's industrial enterprise electrification specialty, has a history of more than 30 years. In 1999, the major was successfully upgraded to the major of electrical automation technology in Higher Vocational Colleges through the reform of Vocational Education in Dalian City. Before the implementation of the "3 $+2+1$ " professional training model, it has gone through the following two stages of development. 


\section{A. Undergraduate "Compressed Biscuits" Talent Training Mode}

At the beginning of setting up the major of electrical automation technology in Higher Vocational colleges, because of the ignorance of the law of the development of Higher Vocational education and no experience to be used for reference, the training mode of professional talents is similar to that of electrical engineering and automation specialties in ordinary undergraduate colleges during this period, especially focusing on the cultivation of students' theoretical knowledge level, mainly to teach profound theoretical knowledge. As for practical teaching, the university is mainly based on verification experiments. There is basically no training course. Basically, it completely ignores the cultivation of students' practical ability. The employment rate of graduates has been declining year by year. This one-sided emphasis on theoretical knowledge inculcation, while ignoring the importance of technical education, and the lack of flexible cultivation of talents in accordance with the social and market demand for vocational education awareness, resulting that the innovative ability of higher vocational students is generally not strong, many students only master simple theoretical knowledge, but lack the ability of planning and practice, and it is difficult to adapt to the social and market demand for talent. In view of the prevailing situation, this profession began to conduct extensive quality tracking surveys of graduates[2]. The results show that, on the one hand, the recognition of graduates is very low, they would rather recruit undergraduate graduates for surprise training, rather than recruit higher vocational graduates; on the other hand, the graduates of this major also deeply felt that the knowledge and ability they learned during the school could not meet the needs of the job. The work process was very difficult, and basically all of them needed to start learning again.

\section{B. Professional Modular Talent Training Mode}

In view of the actual situation of personnel training at that time, it is urgent to reform the training mode of professional talents. Through a certain degree of investigation and Research on the industry and enterprise units, through careful analysis, discussion and research, this paper puts forward a professional ability model of personnel training mode. That is to say, the students majoring in electrical automation technology should have the following main ability modules in the process of completing the whole training task: a professional basic quality module and 8 professional competence modules (electrical and electronic technology operation and application capability modules; basic mechanical processing, fitter operation modules; motor, electrical control and PLC operation and application modules; power supply system operation module; EDA application and simulation operation module; frequency conversion speed application and operation module; singlechip interface technology application and operation module; process control and configuration software (MCGS) application and operation module). According to each ability mode, the courses serving each module are determined in turn, and the curriculum system of electrical automation technology specialty is formed. In terms of teaching mode, the teaching mode of integration of theory and practice is adopted. All the teaching projects are in the training room. If the teaching process involves content that the students have not learned before, it should be supplemented by the follow-up professional teachers.

The mode of professional ability modularization basically follows the characteristics of higher vocational education and the law of professional training, and initially realizes the optimal allocation of theoretical teaching resources and practical teaching resources. In the specific teaching implementation process, the traditional classroom-centered teaching mode is changed to combine theory with practice, combine with posts, work in study, study in work and practice while speaking to highlight students' practical ability, especially the cultivation of professional ability, and begin to focus on the cultivation of students' professional quality.

\section{III. "3+2+1" Talent Training Mode for Electrical AutOMAtion TECHNOLOGY}

In the process of implementing the professional ability modularized personnel training mode, through the in-depth enterprise research and the more detailed quality tracking survey of the graduates, it is found that students who have been trained through the professional ability modularized talent training mode have a certain improvement in their practical ability, but they still have a certain distance from the actual employment needs of enterprises. It is also necessary to carry out more in-depth reform of the professional talent training mode in due course[3].

\section{A. The Connotation of "3+2+1" Professional Talents \\ Training Mode}

Through extensive investigation and Research on local enterprises, higher vocational colleges and universities which set up electric automation technology specialty, and colleges and universities which set up electric automation technology related specialty, in-depth discussion with industry experts and masters of technology, according to the requirement of electric automation technology specialty, according to the requirement of Dalian electric automation technology talents and the conclusion of professional post requirement analysis, and combined with the actual situation of our university, the " $3+2$ +1 " three-stage progressive talent training mode featuring "school-enterprise integration, Work-study Integration and progressive ability" has been formed. Specifically: " 3 " is the first three semesters of method ability, social ability and professional general ability training stage; the so-called "2" refers to the fourth and fifth semester of professional ability training stage; the so-called "1" refers to the sixth semester of comprehensive ability training stage.

\section{B. Characteristics of "3+2+1" Talent Training Mode}

The greatest feature of this reform is to realize the docking of specialty, industry and professional post, the docking of teaching process and production process, and the docking of diploma and professional qualification certificate.

With the "Electrical" professional skills appraisal standard, through strengthening school-enterprise cooperation, the ability to carry out the " $3+2+1$ "talent training mode was implemented in the "school-enterprise integration, work-study alternation", which fully solve the problem of the integration of talent training programs with the professional standards of 
"Electricians", and implement and improve the teaching mode led by 'the integration of theoretical practice". At the same time, centering on quality education and ability training, we will build a two-line teaching model, adhere to the integration of production and education, incorporate the industry qualification access policy and implement the "one book, multiple certificates" system for graduates. Taking the regional market as the guide, relying on the industry and guaranteeing the quality of "double teachers", the training objective of electrical automation technology specialty is accurately positioned.

Relying on innovative training bases, focusing on skills development, strengthening school-enterprise cooperation realize the organic combination of teaching process and production process, the dynamic combination of talent training and social needs, and the close combination of skill training and job requirements. Through the innovative training base, taking the production workshop of the enterprise as the prototype, making full use of the school's venue, human resources and corporate funds, equipment and technology, and closely combining the production task of the enterprise to realize the training of students' professional ability[4].

In the whole teaching process, the classroom should be moved into the training room through the integration of theory and practice, productive training, and internship in accordance with the law of "staged and echelon advancement" so that teachers can explain the students' practical operation while explaining, and students can learn while practicing, and realize the process of engineering and learning throughout the teaching process.

Emphasis should be placed on the quality education of students majoring in this field, especially in vocational quality education. We should adhere to the principle of "learning to do things, learn to be a person first” to train students in this major in an all-round and three-dimensional manner.

\section{INTRODUCE PROFESSIONAL DIAGNOSIS AND IMPROVEMENT MECHANISM}

In order to ensure the sustainable and healthy development of the major of electrical automation technology, this major adheres to the annual quality follow-up survey of graduates on the basis of the "12th Five-Year Plan" and "13th Five-Year Plan" development plan of Dalian Vocational and Technical College, introduces and establishes an all-round internal quality assurance system for electrical automation technology specialty, and continuously carries out diagnosis and improvement work under the framework of the school's internal quality assurance system. The specific measures are as follows.

\section{A. System construction and system formation}

Establish and improve organizational structure. Under the school quality management committee, a quality management team is set up, with the head of the professional unit as the team leader, the professional director and the backbone teachers as the team members. The quality management team is responsible for the construction of the internal quality assurance system of the specialty, formulating the internal quality assurance system of the specialty, guiding the establishment of the target system, standard system and system, and organizing the independent diagnosis and improvement of the specialty.

Build a target system to highlight professional characteristics. We should adhere to the concept of serving regional economic development, through extensive research and demonstration and analysis and comparison of electrical automation technology specialty in brother higher vocational colleges, find out the gap, accurately orientate the professional development, take three years as a cycle, determine the goal of professional construction, and formulate the construction plan. In addition, it is necessary to determine the course construction goals and construction plans, the teachers' team construction goals and construction plans, the students' development goals and development plans, the service management construction goals and construction plans, so as to form a target system that highlights the characteristics of electrical automation technology.

Develop a standard system focusing on cultivating core competencies. Focusing on the strategic theme of "improving the quality of education", we can focus on the core competence and the development of students' sustainable development ability, and formulate specific construction standards for electrical automation technology, including professional construction standards, curriculum standards, teacher team construction standards, student development standards, service and management standards, etc. to form a standard system for electrical automation technology construction.

\section{B. Conduct Self-diagnosis to Achieve Spiral Lifting}

The electrical automation technology profession continues to carry out normalized daily monitoring, medium-term selfcontrol, and annual self-audit work, and establishes a "targetstandard-operation-diagnosis-improvement” PDCA closedloop diagnosis and improved operation mode to form a normalized self-diagnosis mechanism for quality spiral progression.

Daily monitoring. Based on job responsibilities and work processes, combined with work plans, daily self-monitoring should be carried out, the implementation of job responsibilities and the implementation of work specifications should be checked, and the collected data and information should be recorded in real time, and evidence should be retained.

Medium term automatic control. In accordance with the law of school teaching and operation, the professional examination and reform work should be carried out at the middle and end of each semester, and the implementation of various construction tasks should be carried out in the mid-term inspection, and the existing problems should be corrected and improved, and a professional mid-term self-diagnosis report should be formed.

Annual self-trial. Annual self-trial should be conducted annually. The quality management team combines the data of the personnel training state data platform, daily supervision, and the inspection of the medium-term self-control, and conducts a comprehensive self-audit on the construction of the personnel in the personnel training mode, curriculum construction, teacher team building, student development and service and management, correctly improve the existing 
problems and form an annual self-audit report for electrical automation technology.

\section{ConClusion}

China is a pluralistic society; of course, a large number of professional and technical personnel are needed. Our socialist modernization needs not only research-oriented, academic and management-oriented talents, but also practical and highquality builders with strong professional skills. As an important part of higher education, higher vocational education is becoming more important in the reform of higher education system and mechanism. It is equally important to increase the construction of higher vocational colleges and the innovative talent training mode [5]. Dalian Vocational and Technical College electrical automation technology professional training model reform, in line with the development of higher vocational education law. Through continuous exploration and optimization of the talent training model reform, we have achieved fruitful results while promoting the sustainable development of our profession, which can provide a necessary reference for the reform of the training mode of electrical automation technology professionals in brother higher vocational colleges, and has strong reference significance.

\section{REFERENCES}

[1] Zou Xiansheng.Study on the Talent Training Mode of "Engineering and Alternating" in Electrical Automation Technology Specialty in Higher Vocational Education[J].Equipment manufacturing technology, 2009,7(7):197-198.

[2] Shan Ying. Exploring the Training Model and Curriculum System of Engineering and Learning Based on Work Process[J]. Professional technology, 2008,9(97):23-24.

[3] Zhang Chen, Ma Shuchao. Distinguishing the Cultivation of Skilled Innovative Talents[J]. Education and Occupation, 2007, 6(6): 80-81.

[4] Chen Yiwu. Post-task-driven " Capability Module Package" Engineering and Alternate Talent Training Mode [J]. Vocational and Technical Education, 2008, 29 (29): 65-66.

[5] Lu Dayong, Zhang Hongqiang. Practice and Discussion of Teaching Reform Based on Work Process Orientation[J]. Vocational Education Forum, 2009, 5(Chinese): 53-54. 